\title{
ERGONOMICS FOR A HUMAN-RELATED SUSTAINABLE ARCHITECTURE
}

\author{
ATTAIANESE, Erminia \\ University of Naples Federico II \\ e-mail:erminia.attaoanese@unina.it
}

\begin{abstract}
Sustainable buildings are characterized by a natural resources saving approach. Thus design criteria and construction practice have been primarily aimed at designing architecture so-called "green", neglecting, however, human and social aspects. This situation is creating paradoxical results, because new green buildings, designed to address environmental issues, are critical both for energy efficiency, both for occupants concerns. The paper discusses the contribution of ergonomics methodologies and techniques to environmental design of sustainable built environment, looking at architectural design process, from planning and executive stage, to management and use.
\end{abstract}

Keywords: Green building protocols; social sustainability; occupants role; environmental design.

\section{BUILDING DESIGN AND ENVIRONMENT FOR SUSTAINABLE DEVELOPMENT}

Although the social vocation seems to be a fundamental aspect of environmental design of architecture, its relevance results intermittent during the time, probably due to the conceptual extension and the meanings densification that shaped the idea of sustainability associated to the architecture and the built environment. In fact, even if Ficht, since 1970s, defined architecture as the third skin of humans, attention to human and social issues has gradually thinned away, to regain later a renewed propulsive push that today puts environmental and sustainable design $s$ expressions of the mediation action of architecture, promoting the development of a livable, fair and sustainable living ecosystem through the integration of the needs of the environment, society and the economy (ATTIA, 2016).

A key role in this recursive process could be assigned to the evolution of the concept of environment that has, over the last decades, inspired environmental design towards increasingly articulated goals. A first step can be recorded between 1970 and 1980 when, from a widespread idea of environment primarily seen as "climate", intended as a set of physical factors impacting on the buildings and from which to be defended, it moved toward the concept of environment seen as a "resource", in the sense of a source from which material benefits is produced, a reserve of goods from which to draw. These were the years of the first energy crisis, which pushed toward an architecture energy conscious. Centered on the experimentation of active and passive technologies for the containment of consumption and the exploitation of renewable energies, environmental design of buildings focused goals of controlling environmental resources effective exploitation. With the increasing ecological footprint consciousness and the growing awareness of the limits of development, this sort of "instrumental" approach to the environment changed, to embrace the concept of environment as "value", natural and antropic heritage to protect. Building design was thus focused on impacts safeguarding and reducing, by which the issues of the recovery, maintenance and viability of built environments emerged.

After the publication of the Brundtland Report in 1987, sustainability debate officially started, and human beings were put at the center of concerns for sustainable development. The 


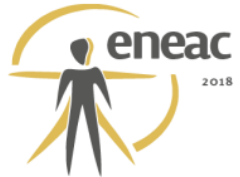

principle of assuring an healthy and productive life in harmony with nature, ideally inspires sustainable architecture, in order to create a balanced human-designed environment.

Nevertheless, if by a theoretical perspective the idea of environment as a structured and multifaceted system arose, the environmental component of sustainable development still prevails on economic and social issues (BERARDI, 2015), contributing to a building design paradigm that is predominantly green, environmentally friendly and energy-efficient, aimed at addressing emergencies due to climate changes, minimizing consumptions and reducing impacts on the natural environment (ATTIA, 2016).

\section{THE MISSING SIDE OF SUSTAINABILITY IN BUILDING RATING SYSTEMS}

In this framework a lot of green buildings rating systems have been developed. They are certification protocols, firstly focused on the building scale, based on performance evaluation systems depending on criteria and indicators able to weight physical features to certify the performance of built environment. Considering the high impact of buildings and construction on the environmentln, there is a general consensus that the widespread of certification tools, globally developed, fostered the inclusion of the life cycle of buildings among the priorities of the sustainability agenda (BERARDI, 2015). However, beyond the individual differences, international comparative studies demonstrate the most widely used rating systems (i.e. BREEAM, LEED, CASBEE, SBTool, GreenStar, DGNB Label, GBC Home, ITACA) are based mainly on the assessment of environmental aspects, with a reductive focus on the social dimension of sustainability (ZUO \& ZHAO, 2014; BERARDI, 2015; ATTAIANESE \& ACIERNO, 2017). UN Goals to end poverty, protect the planet and ensure prosperity for all (UN, 2015) and EU strategies for social benefits assessment (UNI EN, 2012), indicates elements for a safe, resilient and sustainable development, incluging a lot of human-related features of designed environment, such as accessibility and adaptability of sites to their uses; health, safety and well-being that building guarantee to people interacting with it; materials and services provision; actors' involvement in design process. A recent review of the main sustainable buildings rating tools, from the human factors perspective (Attaianese, 2018-in press), confirms that no protocols areas of assessment are "personcentered", while all show limited credits about human-related factors, included into different thematic areas, as outlined below.

\subsection{Health, Safety And Well-being}

Most of human-related credits pertain thermal, acoustic and visual comfort within the categories concerning Health and Wellbeing (BREEM) and Quality of the Indoor Environment (LEED, CASBEE, SBTool). These include essentially the building compliance with technical requirements, based on energy saving standards and on a notion of static comfort, as well as the availability of systems for controlling and monitoring environmental performance and installations by occupants, regardless of the evaluation of their usability. Health issues are usually related to contaminated levels and indoor air quality, and rarely relate to more complex aspects, such as Sick Building Syndrome. Also safety and security issues are generally absent, except in the case of GNB Label, including fire safety, and SBTool, including the assessment of safety in use in Service Quality category. Safety of construction workers is almost excluded.

\subsection{Accessibility And Adaptability}

Accessibility, this is rarely evaluated adequately, as it is often limited to consideration of distance from means of access to services (BREEM) or site accessibility (LEED). It should 


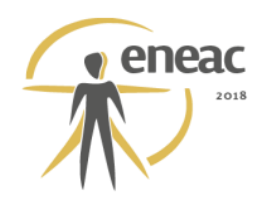

be noted that the involvement of the actors is virtually absent, with the exception of the credit attributed to office buildings, protocols of which include both participatory processes for the ergonomic design of work spaces, both post-occupational thermal comfort assessment, although considered in a rather deterministic way (LEED). SBTool presents numerous criteria in the Service Quality category, organized in more subcategories, specifically focused on the assessment of quality in use, and includes accessibility credits, in terms of Universal Design principles. Also in In DGNB Label points are attributed to Design for All and to the layout quality, as well as adaptability of technical systems, and deconstruction and dismantling criteria of the building. Other credits are in the categories related to the Management and Quality of Service, which in some cases are limited to assessing the availability of a Building User Maintenance Guide (BREEM) or others, considering functionality and maintainability (CASBEE) and the flexibility and adaptability of spaces (CASBEE, LEED).

\subsection{Actors' Involvement In Design Process}

Differently to the protocols for building certifican, those related to the neighborhood scale seems ro be more responsive to the social issues, as in the case of French HQE2, which presents some specific credits related to inclusive communities and many credits inherent local socio-cultural environment, diversity and social integration. Also the recent Italian ITACA Urban Scale Protocol, presents a set of significantly more open and inclusive credits, for evaluating environmental, economic and social sustainability of micro-urban designs. The themes on which the evaluation is based concern governance, including the participatory process, city planning aspects, urban landscape quality, architectural aspects, public spaces, urban metabolism, biodiversity, adaptation, mobility and accessibility, society and culture, economy (ATTAIANESE \& ACIERNO, 2017).

\section{IMPROVING SUSTAINABLE ARCHITECTURE THROUGH ERGONOMICS}

In the last years, reported post-occupation evaluations and evidence-based studies revealed a direct correlation between green buildings and building failures, that often eliciting conflicts among different building performances and occupants actual behaviour. A lot of undesirable effects are registered, not only about human-related concerns and potential risks for occupants and construction workers, but also about building efficiency (Attaianese, 2016). Looking at green certification protocols credits discussed above, part of this concerns may be associated to the current role given to occupants in green building design process, and to the scarce consideration of the human-related factors.

Usually seen as passive elements, people, on the contrary (buildings occupants and urban inhabitants, but also construction, maintenance and operation workers), are today more and more intended as active subjects, on which depend not only energy strategies goals (Janda, 2011), but also the planet global challanges (UN, 2015). In this perspective, the environment becomes an adaptive socio-technical system, featu red by a strong human and relational dimension, a diverse and differentiated community of "interesting and interested" subjects (DU PLESSIS \& COLE, 2011). Such sustainable design process needs to collect and respond to community's needs, thanks to a heuristic and non-standardized attitude, based on adaptation and collaboration, listening and sharing, and hence on inclusion (ATTAIANESE \& ACIERNO, 2017). Ergonomics and Human Factors can improve building design, enhancing sustainability performance during all phases of building lifecycle (ATTAIANESE, 2012; ATTAIANESE, 2016). 




\subsection{The Systemic Approach To Integrated Design}

The systemic dimension of ergonomics is consistent to the "whole system design integration" principle (ATTIA, 2016). It reinforces the sustainability approach "cradle to grave", according to which efficiency have to be guarantee, and then previously analyzed, in terms of possible impacts of the building, as living environment, on the ecological and socio-technical systems of which it is part, in its entire life cycle. The principle of participation and its models, support the integrated process, by including occupants and users in general in two ways: ex-ante, because it improves the design specification with human factors data; ex-post, because it sustain the evaluation of acceptance and sharing degree of the project choices by users.

\subsection{Variability And Diversity For Energy Efficiency, Comfort And Well-being}

Human variability represents a value, analyzed in relation to the final users, in order to define its specificities, such as age, gender, physical capacity and limitations, but also related to cognitive attributes such as intellectual ability, attitude, motivation, habits, cultural level, culture of origin. These aspects are today crucial, since the concept of comfort has changed from a static conditions, to a dynamic and adaptive state, affected not only by human physiological process, but including psychological, cultural and behavioral factors (DU PLESSIS \& COLE, 2011).

\subsection{Analysis Of Activities For The Protection Of Value In Use, Accessibility And Inclusiveness}

Sustainability is a dynamic condition, thus a building to be sustainable has to be useful all its lifelong (COLE, 2009). It need to be able to adapt its performance to its changed need and functions. The human factor approach can implement this attitude in sustainable design, by analyzing the context of use, collecting and detecting user needs and expectations and by observing and describing how users can reach their goals using the building.

\subsection{Ergonomics For Building Maintainability and In Use Operability}

Maintenance is necessary to obtain the high performance of the sustainable building, as it guarantees its efficiency and protects its value in use over time. The study of the human factor can contribute to increase the effectiveness and efficiency of the building, first of all by improving its maintainability. The supportiveness of the maintenance context is fundamental for ensuring the energy efficiency of buildings, with a view to optimizing resources and improving the wellbeing and satisfaction of the occupants. The consideration of Human Factors, supports both the design of maintainability and operability features of buildings components, both the preparation and execution of maintenance activities. Furthermore, a better usability of technical devices does not only lead to a better system efficiency, but also and above all to greater autonomy and awareness of use by end users, a fundamental question for the assumption of environmentally conscious behavior (ATTAIANESE, 2016).

\subsection{Health, Safety And Sustainability, in Use and Construction}

To be sustainable, the building must protect all people who interact with it. It must guarantee safety conditions to whoever realizes it, uses it, managed it (CIB, 2010). This implies that in the design phase, materials, components, and construction techniques must be not only in terms of energy efficiency, economy, or resource savings, but also in relation to their ability to trigger situations of risk for workers. 


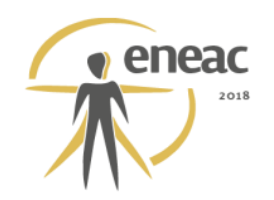

The approach provided by the human factor can support this goals as it provides the criteria for the assessment of a further aspect of resource consumption in the construction process: the human effort required to set-up any construction technique. This is also due to the fact that it is shown that sometimes materials and techniques with similar energy performances prove different in terms of human performance necessary for their application, and that some are more "heavy" in human terms than others, despite these aspects are rarely investigated (ATTAIANESE, 2016).

\section{REFERENCES}

ATTAIANESE E., ACIERNO, A. Environmental Design For Social Inclusion: The Role Of Environmental Certification Protocols. Techne Journal of Technology for Architecture and Environment, N.14, 2017

ATTAIANESE E., Enhancing Sustainability Embodying Human Factors In Building Design. In SORAES M. REBELO F. Ergonomics in Design: methods and techniques, CRC Press, Taylor\&Francis Group; pp. 447-464, 2016

ATTAIANESE E., Green Buildings: The Role Of HFE. In THATCHER, A, YEOW, P. (co-editors) Ergonomics and human factors for a sustainable future, Palgrave-Macmillan, 2018 (in press)

ATTAIANESE, E. A Broader Consideration Of Human Factor To Enhance Sustainable Building Design, Work 41, Supplement 1/ 2012, 2155-2159, 2012

ATTIA, S. Towards Regenerative And Positive Impact Architecture: A Comparisonof Two Net Zero Energy Buildings. Sustainable Cities and Society 26 393-406, 2016

BERARDI, U. Sustainability Assessments Of Buildings, Communities, And Cities, In Kleme, J.J.(Ed) Assessing And Measuring Environmental Impact And Sustainability, Elsevier, pp. 497545,2015

COLE, R.J., Emerging Issues In Building Design. In AGHIGAT, T, KIM, J.J (co-eds) Sustainable Built Environment - Vol. I, Encyclopedia of Life Support Systems (EOLSS), UNESCO, 2009

DU PLESSIS, C., COLE, R. Motivating Change: Shifting The Paradigm, Building and Information, Vol. 39, No. 5, 2011

JANDA, K. B. Buildings Don't Use Energy: People Do, Architectural Science Review 54, 2011

UN, Transforming Our World: The 2030 Agenda For Sustainable Development. 2015

UNI EN UNI EN 15643-1-3, Sostenibilità Delle Costruzioni - Valutazione Della Sostenibilità Degli Edifici, 2012

ZUO, J., ZHAO, Z. Green Building Research-Current Status And Future Agenda: A Review. Renewable and Sustainable Energy Reviews 30 271-281, 2014 